\title{
Problems and Barriers Impeding the Implementation of MagLev Assisted Aircraft Take-Off and Landing Concept
}

\author{
Jozsef Rohacs, Daniel Rohacs \\ Department of Aeronautics, Naval Architecture and Railway Vehicles, Budapest University of Technology and Economics, \\ Budapest, Hungary \\ Email: jrohacs@vrht.bme.hu
}

How to cite this paper: Rohacs, J. and Rohacs, D. (2018) Problems and Barriers Impeding the Implementation of MagLev Assisted Aircraft Take-Off and Landing Concept. Journal of Transportation Technologies, 8, 91-118.

https://doi.org/10.4236/jtts.2018.82006

Received: January 31, 2018

Accepted: April 13, 2018

Published: April 16, 2018

Copyright $\odot 2018$ by authors and Scientific Research Publishing Inc. This work is licensed under the Creative Commons Attribution International License (CC BY 4.0).

http://creativecommons.org/licenses/by/4.0/

\begin{abstract}
Nowadays, the success of the new technology development and deployment process depends not only on technical, technological solutions, but also on solving the non-technological problems and crossing the societal and psychological barriers. A large international European projects, GABRIEL ${ }^{1}$ had developed a maglev assisted aircraft take-off and landing, that was applied to conceptual design of aircraft and required on-board and ground systems, had analysed all impacts (effects of concept deployment on effectiveness, safety, security, noise, emissions) and had demonstrated the safe applicability by concept validation. The applied methodology, used methods and the results of the Gabriel projects had been described and discussed by 55 project deliverables. This paper has a special goal: investigating the problems and barriers of possible implementing of the radically new technology, aircraft MagLev assisted take-off and landing. The study was started by identification and classification of the problems and barriers. After it, the problems were systematically analysed by use of special methodology containing the understanding (description) of the problems, investigation of the possible solutions and discussing their applicability (mainly by use of the Gabriel project results). The paper has three major sections: 1) description of the Gabriel concept and project results, 2) introducing some related thoughts on general aspects of new technology developments, and 3) discussion on the problems and their solutions. The major classes of the problems are the 1) technical, technological problems as developing a radically new solution, landing the undercarriage-less aircraft on the magnetic tracks, 2) stakeholders' problems as
\end{abstract}

${ }^{1}$ GABRIEL-GABRIEL (Integrated Ground and On-Board system for Support of the Aircraft Safe Take-off and Landing_EU FP7L1 project, Grant Agreement Number-284884). 
decision makers kicking against supporting the developments of so radically new technologies and 3) society barriers like society worrying on and fear of future passengers on flying by aircraft have not conventional undercarriage systems. The paper will show that these problems have safe and cost-effective solutions.

\section{Keywords}

MagLev Assisted Aircraft Take-Off and Landing, Problems, Barriers of Radically New Technologies' Implementation, Society Acceptation

\section{Introduction}

The major problems, strategic plans for future developing the economic sectors like aeronautics, aeronautical industry and air transports, too, are regularly defined by visions of high level groups, leading institutions organisations, and companies [1] [2] [3] [4]. The Technology Roadmap 2013 [5] developed by the International Air Transport Association envisions the option of flying without a conventional undercarriage to be in operation by 2032. There is an interesting question: Who does know the idea behind the IATA prediction? How do aircraft take-off and landing without undercarriage system? How will the stakeholders and especially how will the future passengers accept such unconventional solution?

These are very important questions and the problems and barriers against to the implementation of such radical solutions may make difficulties, checks and even may "kill" new ideas.

The European project "Out of the Box" [6] introduced several interesting ideas for possible improvements of the aircraft take-off and landing performance. One of the ideas, using the magnetic levitation technology seems very radical but promising methods. This idea had been developed, analysed and tested by an international project supported by the EU 7 framework program. The GABRIEL (Integrated Ground and On-Board System for Support of the Aircraft Safe Take-Off and Landing) project [7] [8] [9] had developed a maglev assisted aircraft take-off and landing technology. The concept (that might be called as Gabriel concept) was applied in conceptual design (or better to say redesign) of middle sizes aircraft (analogical to Airbus A320) and required on-board and ground systems. The general impact analysis was performed, namely all the major affects of possible deployment of the concept on effectiveness, safety, security, noise and chemical emissions had been evaluated by international project team. Finally, the possible safe applicability of the concept had demonstrated by use of aircraft model in concept validation simulation and physical small-scale tests.

The use of MagLev technology to assist the large civilian aircraft take-off and landing is a really new task, developing radically new solution, and new disrup- 
tive technology. At starting the project, there were no references dealing with such problems, (especially, for example with 1) the evaluation of the possible and applicable solutions, 2) the identification, evaluation and selection of the magnetic technology, 3) the analysis of the required aircraft modifications, 4) the landing of undercarriage-less aircraft on the platform moving on the magnetic track, 5) the fixation of the aircraft on the moving platform, or 6) the development of emergency landing solutions). Finally, 55 project deliverables were completed by the GABRIEL consortia [7]. Each was dealing with special aspects of the developing solution. The most important results have published by series of conferences lectures [10]-[15] and journal papers [8] [9] [16]-[27]. The reader may find a video introducing the Gabriel concept, too [28].

The idea of MagLev assisting take-off, since its introduction by "Out of the Box" project [6] and first application of Gabriel team for EU support, has appeared in other publication, too [29]-[33].

The Gabriel projects have developed a radically new technology, and it has faced with not only the technical problems. Already in application for support, the team met several problems and barriers appeared in evaluation of the proposal. During developing the concept and partly after finishing the project there were identified several important non-technological problems and societal and even psychological barriers. This paper is an unconventional paper, dealing not with the technical solutions, but with the societal barriers and generally with the stakeholders' acceptance of the radically new technologies.

The goal of this paper is investigation of the problems and barriers of possible implementing of the radically new technology, aircraft MagLev assisted take-off and landing. The study was started by identification and classification of the problems and barriers. After it, the problems were systematically analysed by use of special methodology containing the understanding (description) of the problems, investigation of the possible solutions and discussing the applicable solutions (mainly by use of the Gabriel project results).

The paper has three chapters. The first shortly describes the Gabriel concept developments, conceptual design of the aircraft, on board and ground subsystems and summarizes the major results of the impact analysis (evaluation of effects the concept deployment on the efficiency, safety, security, environmental impacts). The second chapter introduces some related thoughts on general aspects of new technology development including the visions on radically new, disruptive technology development, technology identification, evaluation and selection for future solutions and required conditions for deployment success. The third part of the paper discusses the identified problems and barriers, namely special technical problems, problems of decision makers, politicians and major stakeholders and barriers appearing in society acceptance processes. This last point deals with psychological aspects of the users' acceptance, too.

The conclusions summarized the possible solutions of the problems and possible jump over the barriers introduced by the paper. 


\section{Gabriel Concept}

\subsection{Concept Development}

The project was started by study the previously and running projects going back to the Navy [34] electric catapult system investigated at 1946. The end of last century the Navy has returned to development of an electromagnetic aircraft launching system [35] that finally was successfully applied by the US Navy's programme CVN 21 for the future-generation aircraft carriers [36] and the first USS Gerald Ford class carrier was introduced into operation in 2017.

The magnetic levitation technology is investigating by the NASA [37] [38] for launch of spacecraft and by designer of the hypersonic cosmic aircraft MIG-ACS [39] [40].

The Gabriel team has studied 10 different possible solutions for improving the aircraft take-off and landing processes, including for example the fuelling after take-off at high altitude, lifting up-down the aircraft by aerostatic ships, using the cruise-feeder concept etc. [8]. The investigation of the possible solutions had resulted to conclusions, the magnetic levitation assisted take-off and landing is the most promising possible solution.

The GABRIEL consortia developed a series of operational concepts including possible solutions for transition periods, when only few airports will be equipped by MagLev tracks. Their detailed energetic, mass breakdown and operational analysis suggested choosing the principle based on a cart-sledge system (Figure 1). The sledge would include the MagLev elements to enable the accelerations and decelerations on the MAGLEV track, while the cart would be responsible to hold the aircraft, and also-by disconnecting from the sledge-to perform the ground movements on its on wheels.

By choosing the concept, the design requirements were identified and the maglev technologies were analysed. For further detailed studies four MagLev technology was selected 1) EDS SCM: Electrodynamic Null-Flux with superconducting magnets, 2) EDS PM: Electrodynamic Combined Flux with permanent magnets in Halbach Arrays, named "Inductrack System", 3) EMS LSM: Electromagnetic levitation with synchronous long stator propulsion, and 4) EMS LIM: Electromagnetic levitation with Linear Induction Motor. There were created and selected 12 criterion (like levitation capability, speed, acceleration capability, complexity, etc.). In further selection, a mid-size aircraft analogue to A320 was applied for making some physical studies, like calculation of the total

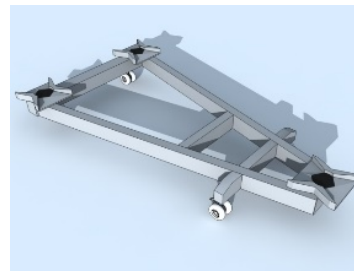

(a)

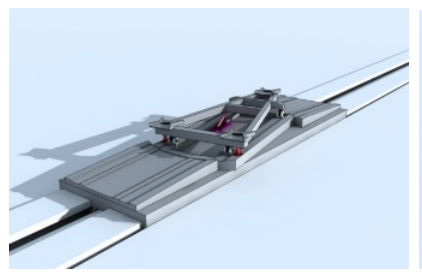

(b)

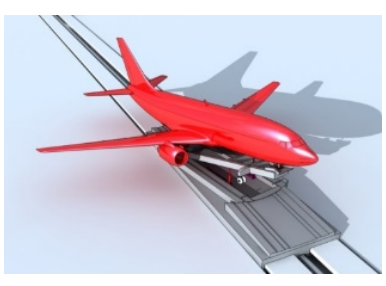

(c)

Figure 1. The cart (a) with sledge (b) in operation (c). 
driving resistance, thrust of linear motors, acceleration, magnetic drag, and so on. After physical analysis and multi criterion decision making, it was found [7] [9] that the most promising system is the Electrodynamic Levitation with Permanent Magnets in Halbach Arrays, often called as the Inductrack concept. In this technology, the levitation is performed by an electro dynamic difference flux system with permanent magnets. The sledge is accelerated and decelerated by an electrical synchronous long primary motor, which is supplied by converter units with variable voltage, current and frequency. The main components of the GABRIEL ground system are the guideway, magnetically levitated sledge/cart system, power chain, linear propulsion, controlling and supervision equipment. It is a rather complicated configuration, but this is necessary to meet the following GABRIEL requirements: 1) maximum speed $75-110 \mathrm{~m} / \mathrm{s}$, 2) acceleration from 2 to $4 \mathrm{~m} / \mathrm{s}^{2}$ and 3) thrust from the engines of the aircraft from $0 \%$ to $100 \%$.

\subsection{Conceptual Design}

For further investigation the developed concept was used to conceptual design the required systems. There were realized the following tasks: definition the requirements, redesigning the aircraft (not having conventional undercarriage system), designing the cart-sledge system, magnetic track, on board and ground rendezvous control system and planning the layout for airport equipped by the new system.

The most important requirements were not reducing the safety and security levels, landing of aircraft on moving platform with accuracy $\pm 1 \mathrm{~m}$, solving the emergency landing.

Only the adaption [7] [9] [14] (redesigning without re-sizing) of aircraft to Gabriel concept (Figure 2) has resulted an excellent performance: reduction in take-off weight of 5.8\% and a decreasing in total fuel weight (mission fuel and reserve fuel) of about $8 \%$ with respect to a reference aircraft (A320). With re-optimization of the aircraft (depending on the optimized variants) the results are reach take-off weight reduction from $7 \%$ to $9.3 \%$ and a total fuel weight reduction between $15.8 \%$ and $18.1 \%$, still compared to the reference aircraft. The best total fuel weight reduction is reached by redesigning the Gabriel aircraft for minimum fuel. These results are extremely positive.

The conceptual design of other systems were applied in determining the required energy supply, required length of magnetic track, testing the possible realization of the strong rendezvous accuracy requirements.

\subsection{Results of the Impact Analysis}

All the impact analysis were performed by use of conventionally accepted methods and the data got from conceptual design [7]-[12] [23] [24]. There were evaluated the magnetic fields by use physical calculation, the aircraft, possible reaching the required accuracy of rendezvous control by motion and control simulation in MATLAB environment, efficiency as cost and profitability with 


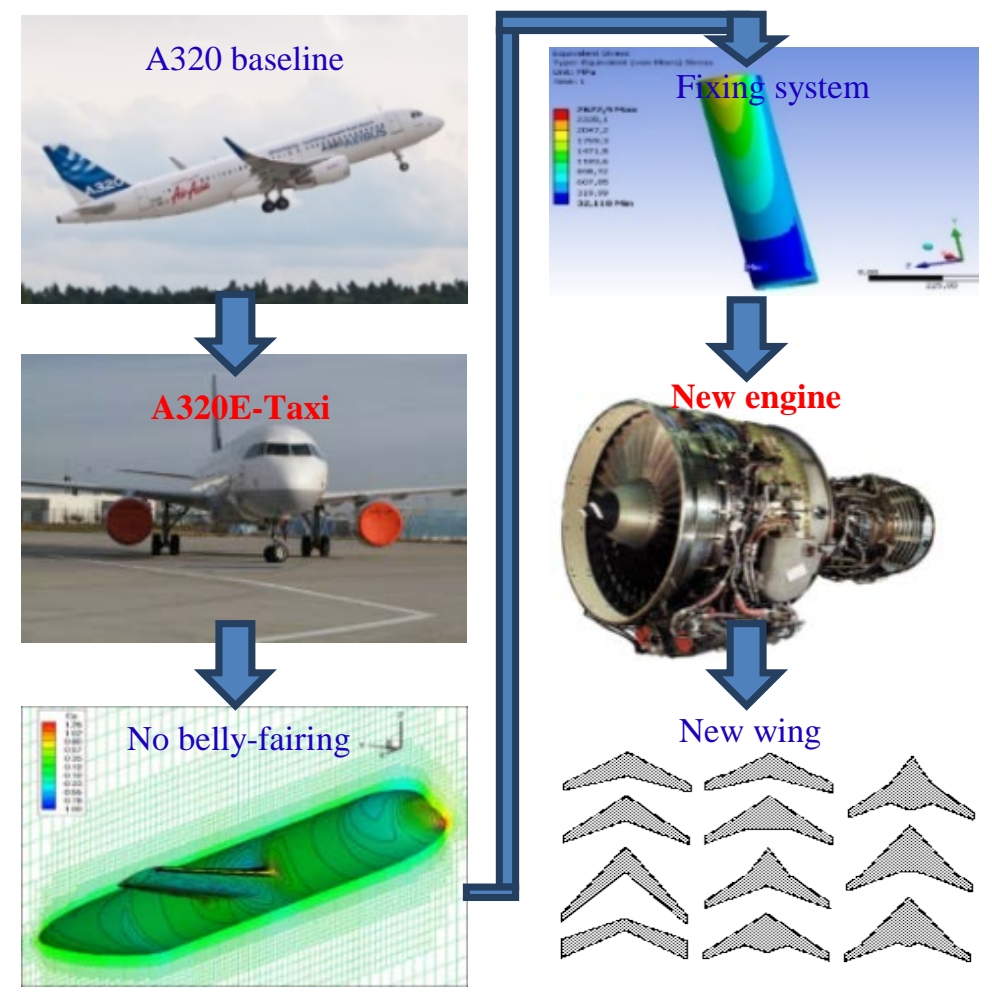

Figure 2. The optimization process of the adapted aircraft.

use of life cycle cost calculations including the required investment into the airport ground systems, too. The environmental impacts were calculated for different take-off and landing scenarios. The noise (Figure 3) and emissions were evaluated depending on the possible take-off and landing procedures and the noise was evaluated by use of awakening methods, too [12].

Altogether, investigations found that (see more detailed description of [7] [9] [12] [17] [23] [24]): the envisioned maglev assisted TOL processes are technologically feasible (as demonstrated with the experiments), while also meeting the requirements (e.g. in accuracy), the deployment of the concept is safe and secure, the concept brings substantial benefits:

o reduction of aircraft weight and fuel consumption up to $9.3 \%$ and $18.1 \%$ respectively (in case of mid-size passenger aircraft),

0 reduction of noise during the take-off (up to $-64 \%$ ) and the landing phases (up to 19\%) depending on the SEL,

0 reduction of the emitted emissions over all phases of flight, but especially over the take-off by $38 \%-58 \%$ depending on the take-off scenario implemented,

0 positive cost-benefit ratio, or cost savings up to $€ 1467.26$ per flight (on a typical European flight with a mid-size passenger aircraft).

The preliminary investigations demonstrated that the GABRIEL concept might be applied to different aircraft sizes with different goals: in case of small and personal aircraft operation the use of unconventional flight scenario might 


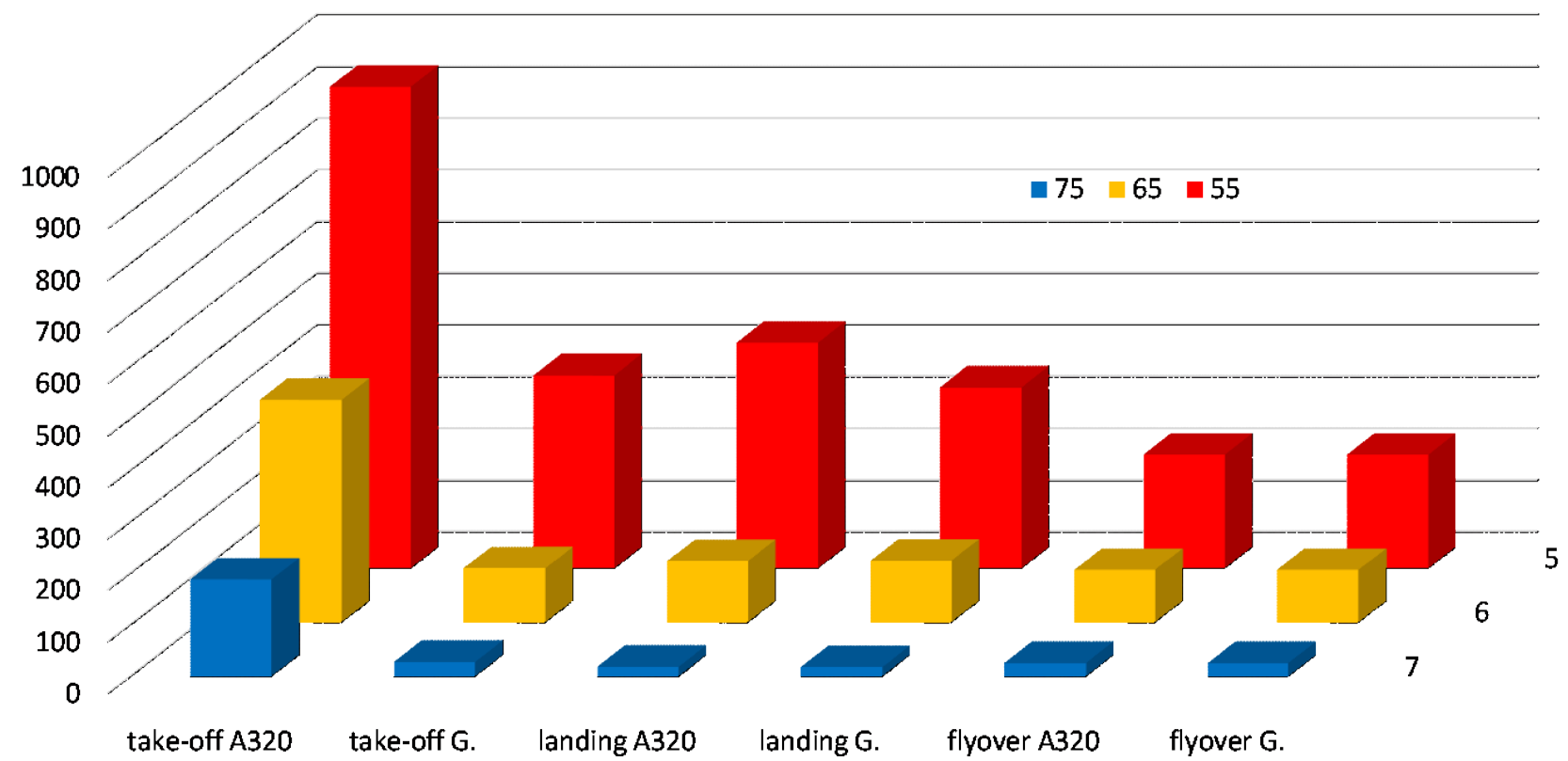

Figure 3. Areas (in $\mathrm{km}^{2}$ ) effected by single aircraft flight phases (vertical axis), at 55, 65 and 75 SEL Sound Exposure Level) noise (in $\mathrm{dB}$ ) defined for reference A320 and G. - Gabriel aircraft (best optimized trajectory).

reduce the noise at the airport regions by up to $90 \%$, in case of mid-size passenger aircraft, the total impact composed from the savings related to aircraft weight, fuel, noise, emissions permits to reach 14 times more profit on a standard European flight (while also covering the required investment costs) in case of large aircraft (like A380) the total weight reduction and fuel economy might be maximized.

\section{Development of the Radically New Technologies}

\subsection{Disruptive Technologies}

The technology as a term has many different definitions. The most used two of them have rather different approaches to evaluation of the technology [41] [42]. First defines the technology as description of methods of production. This means the technology includes the production infrastructure, as production machines, energy supplies, etc., applied materials and used organizational process of production. This is a physical approach, and it might be called simple as "doing things" [43]. According to the second definition, the technology includes the knowledge as information about how the inputs are transferring into the products, too [41]. In this case, the information defining the technologies and innovation processes is calling as "knowledge" [43], the technology as knowledge-based. Unfortunately, the information often-even on scientific level-does not fully available. For example, the computers are very complex products, that were difficult to develop and they were difficult to use. Because the results, developing the information applicability fits people's needs, the companies vent through of changes its product development philosophy [44] [45]. 
The developments of the new technologies appear in three different forms. The innovative technologies improve [46] the existing technologies, existing solutions (Figure 4). Such technologies are often called as sustainable technology that sustains the continuous development of the existing systems.

The radically new solutions are called as development of disruptive technologies (Figure 4) [47] [48]. Such technologies destroy the existing systems and develop new solutions and even market for these new solutions (products or services). Finally, the new technologies overcome the existing technologies (as gas turbine caused a step changes in air transport system). So, the disruptive technologies initiate radical changes in the given area of economy and a step change in the technological level [48] [49].

The development and implementation of disruptive technologies might however generate certain problems for the companies-especially for large ones [47] [49] [50]. Following to McBreen [51] notes-1) the market progress separates from the technology progress 2 ) the disruptive technologies needs a new market, 3 ) the new markets enabled by disruptive technologies require significantly different capabilities, 4) or the information required to make investment decision is often non existing. So, the companies must focus not only on maintaining the technology and product development, they must evaluate the future needs of peoples and stakeholders and they must develop radically new, disruptive technologies and products parallel with the market development.

Finally, the third type of new technologies is the subversive technologies that cause radical changes on the society levels.

According to the US practice [52], more than every second of the radically new ideas, solutions and technologies are burned by the small companies, as they make even risky decisions on short-time, and not afraid of working on the promising but challenging ideas. At the same time, $87 \%$ of research and development cost is supported by the large companies [52]. The (large) companies often deal with the development of the innovative technologies, only, to save their market. However, if the companies are not working on the new, even on radically new technologies, not developing the knowledge of their employees and concentrate their activities mainly on the (aggressive) market defences, they

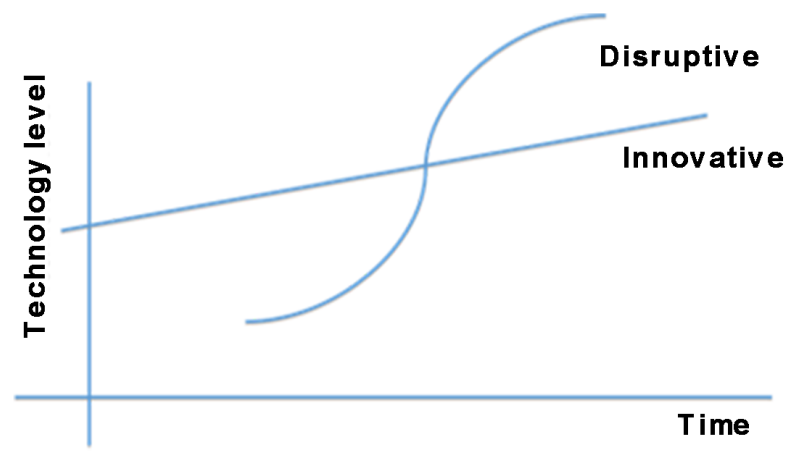

Figure 4. Changes in technology levels by developing different technologies. 
may lose their market position. It may explain why $60 \%$ of companies had dropped out from the exclusive club "Fortune 500" for 30 years [53].

The development of the radically new technologies and product required creativity and unconventional ways of thinking from developers and courage from decision makers and investors. That was well understood by the European decision makers creating the new Horizon 2020 programs when they had included into the program special calls for supporting the radically new and risky ideas, too. However, for example in aeronautical programs, still too large amount of supports is dedicated to mega projects pushing by large industrial players. As it was outline by this point, the innovation theory teaches that the large players are not so good in future, really new technology developments.

\subsection{Identification, Evaluation and Selection of the New Technologies}

The Gabriel project [7] had developed concept applying the magnetic levitation technology to assisting the aircraft take-off and landing. For realizing the project within the planned time and support, the Gabriel team had used three major governing methodologic principles: 1) systems engineering in project management, 2) selecting the best possible concept and magnetic technology and 3) using the conventionally available methods and software in conceptual design and impact analysis.

Nowadays, many radically new, disruptive technologies are appearing and the lives of technologies are reducing. Therefore, the technology identification, evaluation and selection (TIES) for future products and services required becomes to top level of product development and requires a special approach. It mobilizes a large set of procedures that could be applied in task, goal and objective oriented individual processes. There are several theories like defined by [54], but no one for general use. There is no unique solution, each case requires special approach.

The TIES can be divided into two groups. In first and simplified cases, many different methods and tools [55] can be utilized like brainstorming, Delphi method, idea advocate, creativity assessment, cluster analysis, dendogram, matrix data analysis, factor analysis, opportunity analysis and reverse brainstorming that could be applied together in process of technology evaluation.

The second group of TIES is characterized by systematic and complex approach. The TIES developed by Kirby [56] [57] [58] was adapted to selecting the magnetic levitation technology by Gabriel team. The methodology of Kirby [58] contains iteration process having 8 steps that are applied by the following ways:

- Problem definition: actuality, problem to be solved, costumer (stakeholders' requirements), expected budget (or benefits), possible scheduling, etc.

- Concept space definition: applying the morphological matrix, analysis of alternative concepts, definition of the design spaces.

- Modelling and simulations: that may start with visual and verbal models help in understanding the developing concepts, through simulations based on 
physical principles, up to the stochastic (like Monte Carlo) models. The simulations catalyse the definition and evaluation of the system constraints, limitations, levels of confidences. Developing and using the response system equations describe the relationships between several explanatory and response variables, etc.

- Investigation of the design space: based on deterministic and stochastic analysis, investigation of the sensitivity functions, effects on changes in metrics on the design spaces, use of probability density functions, fast probability integrations, etc. methods combining with stochastic simulations.

- Evaluation of the system feasibility: for defining the constraints and system feasibilities needing improvements further improvements.

- Technology identification: defining those technologies that may perform the required system features. This might be the widest part of TIES. It combines the study the morphological, compatibility, technology impact matrices, evaluation of the technology readiness of the systems, sub-systems, elements and technology mapping technique.

- Technology evaluation: that is based on the technology forecast, forecast of appearing and emerging new technologies, physical aspects of technology application (like requirements initiated by flight operation, airport operation, societal expectation), decision making.

- Technology selection: multi-criteria, multi-attribute decision making with use of special methods as genetic algorithm, evolutionary and revolutionary techniques, combining with resource allocation, etc.

The simplified and goal and object oriented TIES applied by Gabriel project is shown in Figure 5.

\subsection{Conditions for Successful Deployment}

The developers often think all others and the systems are faulty if their products are not so supported and welcome by market, while the success of new product might be predict. During developing the Gabriel concept, there were identified four important aspects that may catalyse (or fail) the success.

- Role of market

The modern product development is initiated by market needs. This is true for case of developing the revolutionary new, disruptive technologies, products, too. All the developments may have success in case of providing something that needs by people (see example of computer development cited in point 3.1).

The market may cut the product development because the price conflict, when the price of future product may not accepted by market (See for example price conflict detected by [59], according to which, the price of unit of strategic bomber may reach level of the US defence budget by 2060. Of course, after this important prediction the strategic plan of military aircraft developments had been changed).

The requirements to safety, security and today the environmental impacts growth barriers and constrains for new product developments. 


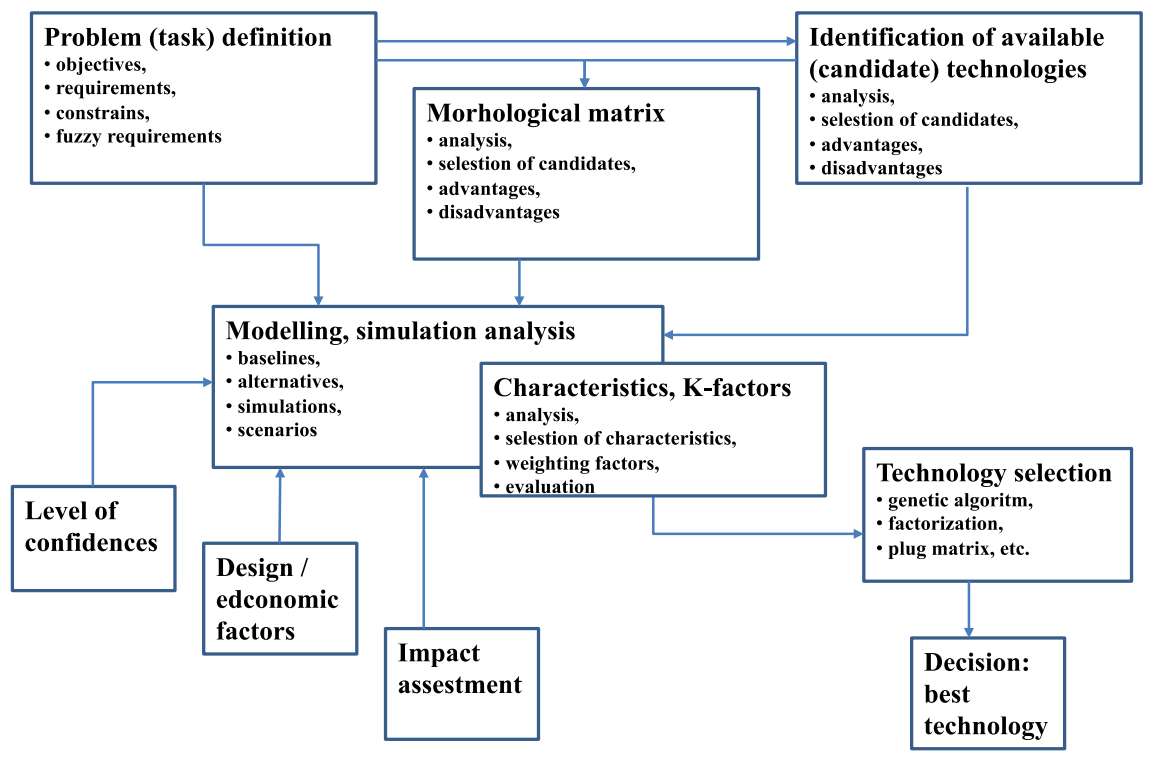

Figure 5. The applied methodology for technology identification, evaluation and selection.

Finally, another important aspect is the time to the market. As it will know, the time from burning the new idea until its deployment in aircraft may long 20 - 25 years. Nowadays, in area of "profit is god" the profit oriented companies cannot mobilize serious financial sources for very radical projects.

- Methodology and process management

The Gabriel project was managed by use of NASA systems engineering [60] [61] that includes 1) dividing the product life cycle into phases and investigating of the large systems as the set of sub-systems, 2) introducing metrics into the development processes, 3) developing the product for cost effectiveness, 4) describing a set of engineering and management tools (as introducing the " $\mathrm{V}$ " model of development, the probabilistic treatment of cost and effectiveness, handling with uncertainties, working on stakeholders' expectations, etc.).

The project used high-level sophisticated software and method, too, as multi-objective, multi physical and multi-disciplinary (like adaption of aircraft to MagLev assisted take-off and landing (see Figure 2). Of course, during developing the principal solutions, production and operation concept, all the "new sciences" as innovation theory, logistics, lean technology, virtual technology, etc. had been used, too.

- Technology and product life

The technology life is a time under which the technology performances are continuously increasing and not replacing by other (better) technologies [62]. It is well understandable; the technology life has embryonic, growth, mature and aging parts. It, as the product life, follows the " $\mathrm{S}$ " curves known from innovation diffusion theory [63]. Successful product (generating profit for their developers and producers) can not be used the embryonic, or just growing technologies [62].

Applying the innovation diffusion theory to deployment of the disruptive 
technologies, a chasm (Figure 6) can be detected at the time period when the technology satisfied the basic needs [46]. Until this, the diffusion of new product into the market is pushed by technology (technology driven, technology dominating period). After it, the adopters (buyers) of the new product, has not special interest in further increasing the technology level (Figure 6), they satisfy the product and want reliable and cost effective, namely low cost product. This is the user experience dominated area.

The investigation of the technology and product diffusion processes, show two interesting aspects. At first, the innovative companies developing the disruptive high technologies and product cannot growth up to large company levels (even they hate to growth up), because they have open eyes, thinking out of the box culture (required for developing the radically new technologies) and cannot understand the different between the early and later developments. Technology is easy to change, the culture is hard. At second, the large companies evaluating the radically new, emerging technologies and their best customers see them as overpriced and underpowered. In fact, Brower and Christensen [47] show that asking your customers is the wrong approach.

At the same time, the new technology and product developer often make a simple mistake: they love their ideas too much. They "have no interest" in evaluating the life of their idea, technologies planned to apply. On the other hand, the foresight describes the possible future that may occur. It uses qualitative, semi-quantitative and quantitative methods. According to the practice the qualitative methods as literature review, expert panels, scenarios, conference and workshop materials, brainstorming, etc. are applied [64]. From quantitative methods, the modelling applied in $6 \%$ of foresight development and the trend extrapolation was used in $17 \%$ of investigated foresight, only. Generally, the foresight deals with the possible future depending on the appearing the new disruptive technologies, the possible deployment of the emerging technologies, changes in needs of society and economy and actions applying to "managing" the future.

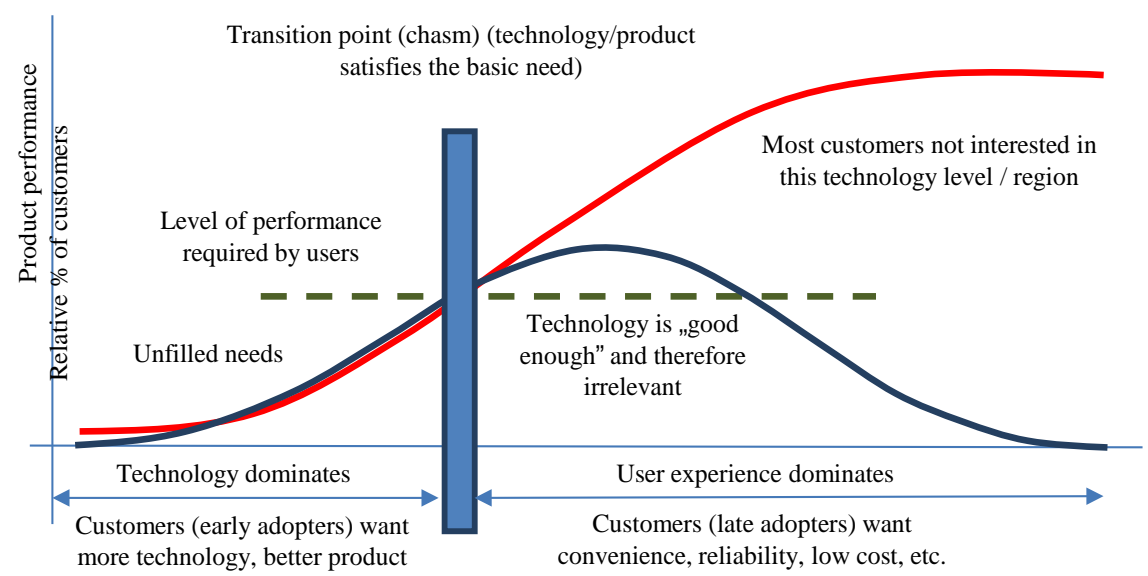

Figure 6. The needs satisfaction curves (upper figure) and the change in costumers as a technology matures (lower figure) [46]. 
The innovative companies developing the disruptive technologies often also are not applying the roadmapping.

- Society acceptance

As it was outlined, the disruptive, revolutionary new technologies might be developed by people thinking out of the box [6] [65]. Generally there are many articles published on impact of technology on society (see for example [66] [67]), while the society, social acceptance of new technologies are investigated as acceptance of given new technologies. For instant, the paper [68] deals with social acceptance of renewable energy. Its idea on triangle of social acceptance might be generally apply. According to this triangle, the social acceptance depends on the 1) socio-political acceptance (acceptance of new technologies by the public, stakeholders and policy makers), 2) community acceptance (procedural and distributional justice, thrust) and 3) market acceptance (acceptance by consumers, investors and intra-firms). In case of operating the aircraft without undercarriage systems that land on the platform, moving on magnetic track, the society acceptance, acceptance by users (people, airlines, airports) may play determining role in future success of the concept deployment.

\section{Problems and Barriers}

The radically new solutions, technologies always meet serious problems and barriers impeding their application, faster deployment. Especially, in case of "out of the box" projects [6] [65], the stakeholders may even create the problems and barriers or afraid of appearing problems. The diffusion of new product depends on many factors including the economic, technological and social aspects [69] [70] [71]. In some cases, the stakeholders are accepting the new products on relatively easy ways [67] [72] [73] because the new products really meets their needs (like mobile phones) or/and have strong political supports (as electric cars). In other cases, when the original solutions or technologies are planned to implement to the part of the total systems (like developing the electromagnetic brake [74]) the acceptation problems are reduced, too. In cases of developing new approaches to operator load measurements and management combining the new technologies with possible measurement of the psychophysiological (mental) condition of operator the implementation meet resistance of user-operators as car drivers, aircraft pilots, air traffic controllers [75] [76] [77] [78] [79].

\subsection{Special Technical, Technological Problems}

At first sight, use of MagLev technology to support the aircraft take-off and landing is so radical concept that generates many technical, technological problems. The Gabriel project [7] had demonstrated, this concept can be realized safely and cost-effectively even today, by utilizing the available technologies. Of course, several problems needs further investigations and creating some solutions. The most important three problems are the followings.

- Required energy support-energy balance

The energy problem is generating by the weight of the cart-sledge system that 
must be accelerated by the aircraft together. The chosen Gabriel concept (Figure 1) minimizes the weight of the cart-sledge system mass of which equals to $80 \%$ - $135 \%$ of the accelerating aircraft mass. The required energy and power were determined for the 5 scenarios (Table 1) by applying the methods of aerodynamics and flight mechanics calculations and physical equations for operation of the magnetic tracks. The total drag is composed from aerodynamic drag of airplane, undercarriage friction, electrodynamic resistance and platform aerodynamic drag. Here, the undercarriage friction is appearing at moving of cart-sledge at low velocity on rolling wheels, because the selected Electrodynamic Levitation with Permanent Magnets in Halbach Arrays can not work at low velocity. After reaching the velocity $1 \mathrm{~m} / \mathrm{s}$, the platform will be able to lift the airplane and itself (for levitation height $3 \mathrm{~cm}$ ) and system will be accelerated by MagLev.

The Figure 1 contains the required energy supply power for case using the medium voltage transformers and $20 \mathrm{kV}, 50 \mathrm{~Hz}$, three-phase.

An important advantage of using the MagLev track is the possible and easy recovery the applying energy during the deceleration. The Table 2 demonstrates the results of energy balance calculations. As it can be seen, the $32 \%-36 \%$ of energy might be recovered during a take-off-landing cycle. The percentage of regained energy will be reduced for $4 \%-2 \%$ in case of take-off-take-off and

Table 1. Take-off scenarios and required ground supply power.

\begin{tabular}{ccccc}
\hline Scenario & $\begin{array}{c}\text { Take-off speed } \\
(\mathrm{m} / \mathrm{s})\end{array}$ & $\begin{array}{c}\text { Acceleration } \\
\left(\mathrm{m} / \mathrm{s}^{2}\right)\end{array}$ & $\begin{array}{c}\text { Engine power (\%) in } \\
\text { ground running }\end{array}$ & $\begin{array}{c}\text { Required ground } \\
\text { supply power (MVA) }\end{array}$ \\
\hline Reference & 75 & Not predefined & 100 \\
Conventional I & 75 & 2 & $\cong 0$ & 29 \\
Conventional II & 75 & 3 & Varying & 29 \\
Accelerated & 75 & 4 & 100 & 55 \\
Unconventional & 110 & 5 & & 55 \\
\hline
\end{tabular}

Table 2. Energy balance of the take-off-landing cycle.

\begin{tabular}{|c|c|c|c|c|}
\hline Scenario & \multicolumn{2}{|c|}{ Conventional I } & \multicolumn{2}{|c|}{ Unconventional } \\
\hline Operational segments & $\begin{array}{c}\text { Energy } \\
\text { spend }(\mathrm{MJ})\end{array}$ & $\begin{array}{c}\text { Energy } \\
\text { regained }(\mathrm{MJ})\end{array}$ & $\begin{array}{c}\text { Energy } \\
\text { spend }(\mathrm{MJ})\end{array}$ & $\begin{array}{l}\text { Energy } \\
\text { regained }(\mathrm{MJ})\end{array}$ \\
\hline $\begin{array}{l}\text { Acceleration sled + aircraft to take-off } \\
\text { speed ground electric energy }\end{array}$ & 570 & & 640 & \\
\hline $\begin{array}{l}\text { Acceleration sled + aircraft to take-off } \\
\text { speed energy from engines }\end{array}$ & & & 350 & \\
\hline Sled deceleration to standstill & & 110 & & 250 \\
\hline $\begin{array}{l}\text { Acceleration of sled to the } \\
\text { aircraft landing speed }\end{array}$ & 180 & & 160 & \\
\hline deceleration of sled and aircraft & & 130 & & 170 \\
\hline Total (MJ) & 750 & 240 & 1150 & 420 \\
\hline Percentage of regained energy & & $2 \%$ & & $5 \%$ \\
\hline
\end{tabular}


increased up to $62 \%-72 \%$ in landing-landing cycles because of returning the sledge between the usage to the initial position. For reducing the time between the take-off and landing procedures, the sled must be return during 1 minutes.

- Rendezvous control

It is not questionable, the rendezvous control, namely control of landing of undercarriage-less aircraft on the sledge moving on magnetic track is the number one problem of the MagLev assisted aircraft take-off and landing. This is not a simple technical problem, but it is a major, might be most important problem that may bar to deployment of the concept, because the stakeholders, especially the users, future passengers may not accept the solution considered so dangerous.

The Gabriel project [7] 1) had investigated this problem by simulation method, 2) had demonstrated the possible solving the problem by small case concept validation tests and 3) had developed several methods, tools for improving the rendezvous control [7] [9] [15] [21] [22] [23] [26].

The applied simulation model was created in MATLAB environment and integrates a series of sub models, as middle-size civilian aircraft (adapted from analogical to A320 type) aircraft, aerodynamics, engine, aircraft motion, sledge motion, relative position measurement, wind, air turbulence, actuators, sensors, automatic flight control and rendezvous models. The required accuracy of rendezvous was defined as $\pm 1 \mathrm{~m}$. The simulation results showed that (Figure 7) the required accuracy might be realized even in case of strong air turbulence or side wing required to use the crab manoeuvres. The available conventional technologies, without special improvements may results to $\pm 1.6 \mathrm{~m}$ in lateral and $\pm 8.3 \mathrm{~m}$ in longitudinal directions.

The concept validation tests were realized by use of small unmanned air vehicles as validation aircraft that landed on the electric cart and on the test magnetic track built specially for this purposes with length of $6 \mathrm{~m}$ (Figure 8).

The first system was intended to analyse the practical feasibility of the developed control concept. The relative position of the sledge and UAV was measured by optical methods using a special marker painted on the sledge. Later, the analogical principle was developed and applied by DLR to manage the UAV landing on the top of a moving car [80]. The second series of tests were introduced to validate the overall GABRIEL concept.

The results had demonstrated the feasibility of the concept.

Final conclusion was that, the rendezvous control needs further investigation and improvements. The project had developed several ideas for possible improvements of the rendezvous control, like improving the sledge dynamics, increasing the effectiveness of the actuators systems by wide use of distributed micro sensors, applying the gust elimination technology, making control with feed forward and predictions, integrating the ground and on board systems including sensing, etc. It was developed a possible display system for the integrated ground-on-board rendezvous control system (Figure 9). 


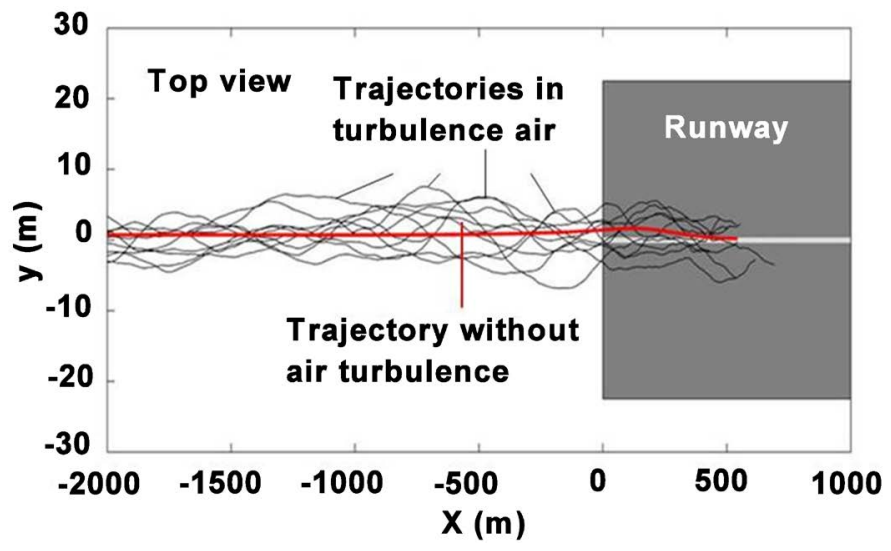

Figure 7. Simulated GABRIEL automatic landing aircraft trajectories for scenarios without turbulence (red) and with turbulence (black, 10 simulations) in 25 knots lateral crosswind.

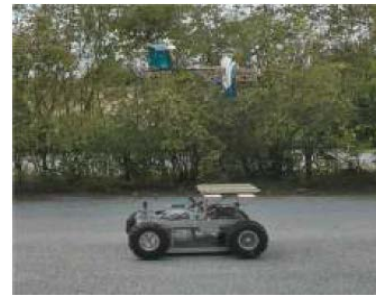

(a)

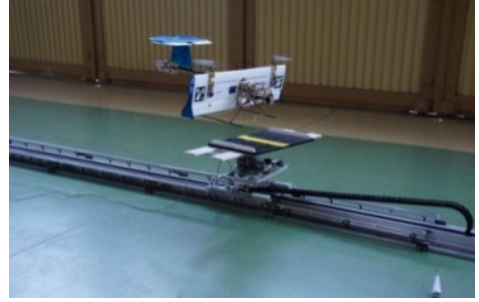

(b)

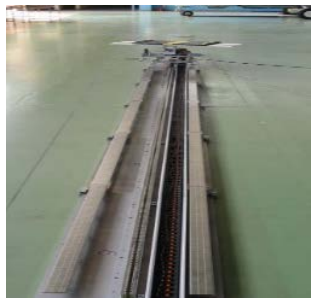

(c)

Figure 8. The practical concept validation tests: (a) UAV landing on electric car; (b) developed test track; (c) landing of the validation model on test track.

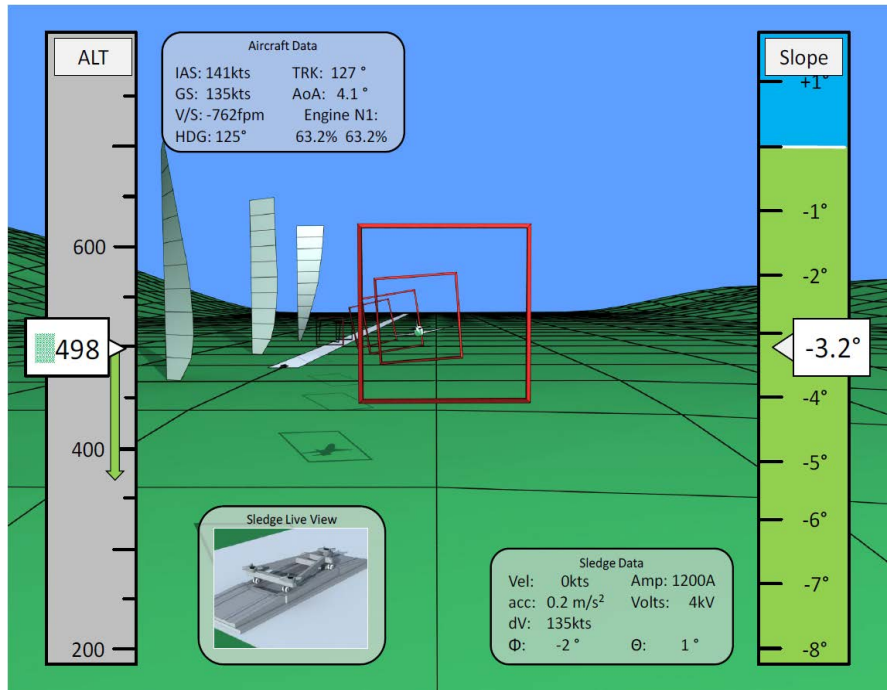

Figure 9. A possible display dedicated for rendezvous control.

- Real environmental impact

The environmental impact analysis showed that, the use of the Gabriel concept will reduce the fuel consumption up to $18 \%$ in case of mid-size passenger aircraft, and considerable reduce the noise at airport regions (Figure 3) and re- 
duces the chemical emissions for $40 \%$ - $60 \%$ calculated for ICAO landing take-off cycle after optimisation of the climb and approach procedures. The noise and chemical emission reductions are questionable, because, or the airport size, namely runway length (including the decelerating the sled after aircraft take-off) should be increased for another $30 \%-60 \%$ or during the take-off the aircraft engines must be used, too. There was elaborated an unconventional take-off and climbing scenario (see Table 1) developed to reach maximum noise and emission benefits (Figure 10). In this case, the aircraft is launched with increased velocity up to $110 \mathrm{~m} / \mathrm{s}$ or even more, the kinetic energy allows to aircraft to climb to level $300-600 \mathrm{~m}$, in order to fly over the noise sensitive areas, and then use own engines. This is not a simple unconventional take-off procedure, but it is an originally new flight operational mode.

Another problem with emission is caused by use of electric energy, that is generated partly not from renewable clean sources. So, the global and greenhouse effect may not so excellent.

\subsection{Problems of Stakeholders}

The stakeholders like to operate the existing systems. Introducing new and especially radically new technologies and solutions always generate some extra problems for stakeholders. They (may) have many problems with deploying the MagLev assisted aircraft, too. The policy makers, aircraft producers, and operators (airlines, airports) have problems associated with cost, safety, and security aspects. The following problems may cause the most serious barrier to deployment the Gabriel concept.

- Required large investments

The decision makers and the airport operators' fear with good reason from extra high investments required to spend for further research and especially for preparing the airports for operation of the MagLev assisted aircraft. This fear partly might be supported by the relatively old information. The cost of MagLev train investment projects has dropped for $40 \%-60 \%$ for last 20 years. The cost of guide way infrastructure involves the $30 \%$ of the total project investments and equals to 20 - 35 MEUR per km. Nowadays, the required investments for MagLev train projects are comparable to the high speed train projects. Even the cost of lane $\mathrm{km}$ of the grade-separated transit way (for busses) may reaches the $25 \%$ $30 \%$ of the Maglev Train project cost for the same $1 \mathrm{~km}$ line [81]. So,

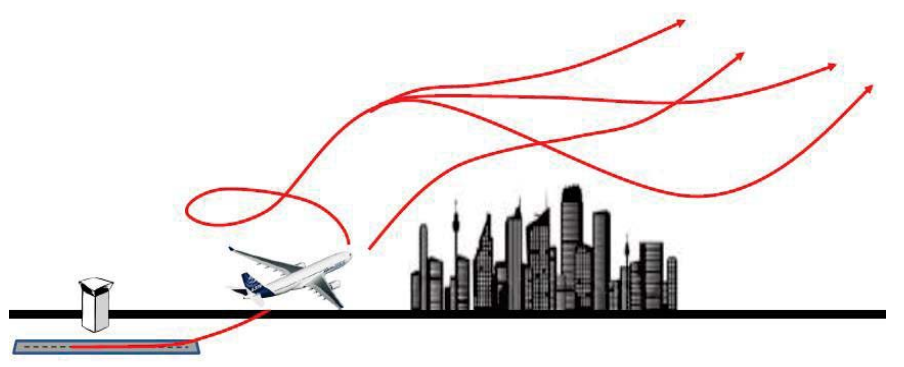

Figure 10. The unconventional take-off and climb scenarios. 
building of $2 \mathrm{~km}$ grade-separated lane in mega polis requires support enough for building about $1 \mathrm{~km}$ MagLew guideway, Maglev track.

The evaluation and analysis of deployment the Maglev assisted aircraft [7] showed that

1) the required investment is really much more higher than infrastructure development of the conventional airport (Figure 11), while

2) the operational cost determined for landing-take-off cycle is slightly better for MagLev assisted aircraft, and

3) due to large economy in fuel reduction by use of undercarriage-less aircraft optimised for use of Maglev technology 1300 - 1500 EUR can be saved on each flight of middle-size passenger aircraft.

- Innovation diffusion time and chasm

The policy makers and the professional stakeholders are familiar with the innovation diffusion process, with the "S" curve (see Figure 6). They know, the history of air transport development can be represented by two " $\mathrm{S}$ " curves [4] [82]: pioneering and commercial aviation. Now, we have to find that major technology that may introduce the third "S" curve of development. However, they may not satisfy the MagLev technology is that what may define the future, third " $\mathrm{S}$ " curve of aeronautics; they think the deployment of this technology required too long time yet and the technology may not pass the chasm (Figure 6) because the users do not need and will not accept such revolutionary new technology.

This opinion of the stakeholders might be explained by several facts as the technology required further complex and expensive research, the aircraft procedures must change the aircraft, the airport operators must spend a lot of money for adapting the infrastructure, and the real and rather excellent profit will be realized at the airliners, only.

As it was previously underlined, the profit on one flight the 1300 - 1500 EUR that several times greater than the profit realized today with use of conventional aircraft. So, better to think on the sharing the profit and accelerating the research, development and deployment processes.

Principally, the Gabriel project [7] was finished in planned time, without changing in preliminary defined program and realized all the intendent research, analysis, evaluations. This project one of those projects that pioneers in the global aeronautics research and maintains leading position of Europe in this area in developing the MagLev assisted take-off and landing of civilian aircraft.

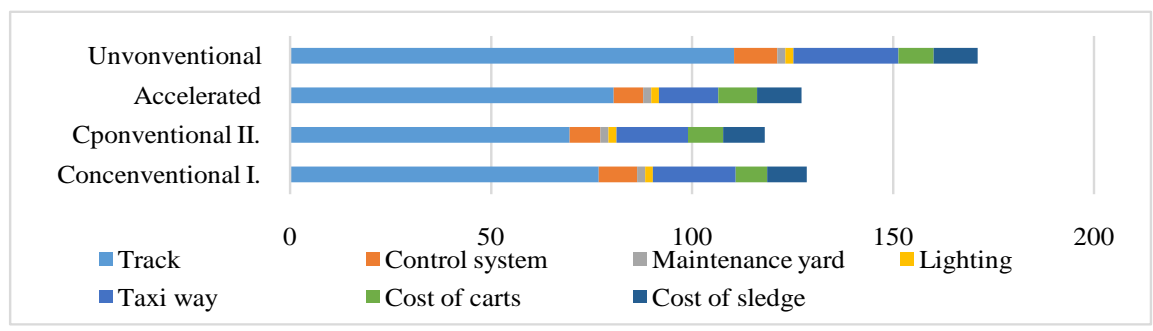

Figure 11. The required investment cost (MEUR) of the different scenarios (see Table 1). 


\section{- Security}

It seems, the security is a real problem, because the new, the radical new technologies may call attention of terrorists. Due to the out-of-the-box character and more particularly the new system elements of GABRIEL concept relative to the conventional air transportation, a new security evaluation method was defined. The security risk was calculated as resulting effects of different factors, as assets, vulnerability, outcomes of attack, threat, violence and „success” of possible actions. The risk factors were defined for the conventional aircraft and the ratio of increasing/decreasing of these factors was evaluated separately.

In results, the potential security risks were identified for all the major sub-systems, such as aircraft, aircraft ground and flight operations, airport, magnetic tracks, energy supply systems, ATM, rendezvous system. The investigations clearly showed the critical elements of the Gabriel system are the armed attack of the maglev track and the armed or cyber-attack of the rendezvous control system. The determined risks were equal to $2.5 \cdot 10^{-6}$ and $0.2 \cdot 10^{-6}$ consequently. These elements need further improvements for considerable reducing the security risk.

\subsection{Barriers in Society Acceptance}

The passengers of future air transport afraid of possible strong magnetic fields generated and may effect on their health as well as they may not accept to use the airplane without undercarriage systems.

- Possible effects of magnetic fields

According to the regulations, the dangerous level of the magnetic field equals to $2 \mathrm{~T}$ as maximum ceiling and $60 \mathrm{mT}$ as 8 hours weighted average for full human body and in case of static magnetic field [83]. The time varying magnetic field has greater effect on the human health, therefore the same limits are 600 $\mu \mathrm{T} /$ frequency and in case of $50-60 \mathrm{~Hz}$ frequency the allowed maximum weighted average magnetic flux level is $500 \mu \mathrm{T}$ for 8 hours duration [81]. These limits are considerably reduced for pacemaker users: $500 \mu \mathrm{T}$ and $100 \mu \mathrm{T}$ as 8 hours weighted average in case of static and $50-60 \mathrm{~Hz}$ time varying magnetic fields.

The magnetic field was thus simulated and analysed for different situation and scenarios. The results like it can be seen in Figure 12, clearly shows no negative impact on the passengers, operators, crews or aircraft avionics (the black colour indicates the induction over the dangerous level, as 8 hours weighted average for full human body in case of magnetic field frequency generated at the take-off velocity of $75 \mathrm{~m} / \mathrm{s}$ ).

- Safety of landing

Most of the people watching the simulation video of Gabriel project [28] think that the operation of undercarriage-less aircraft and their landing on the platform moving on magnetic track is too dangerous solution. This paper may and try to call up the attention of such people on several important arguments, as 


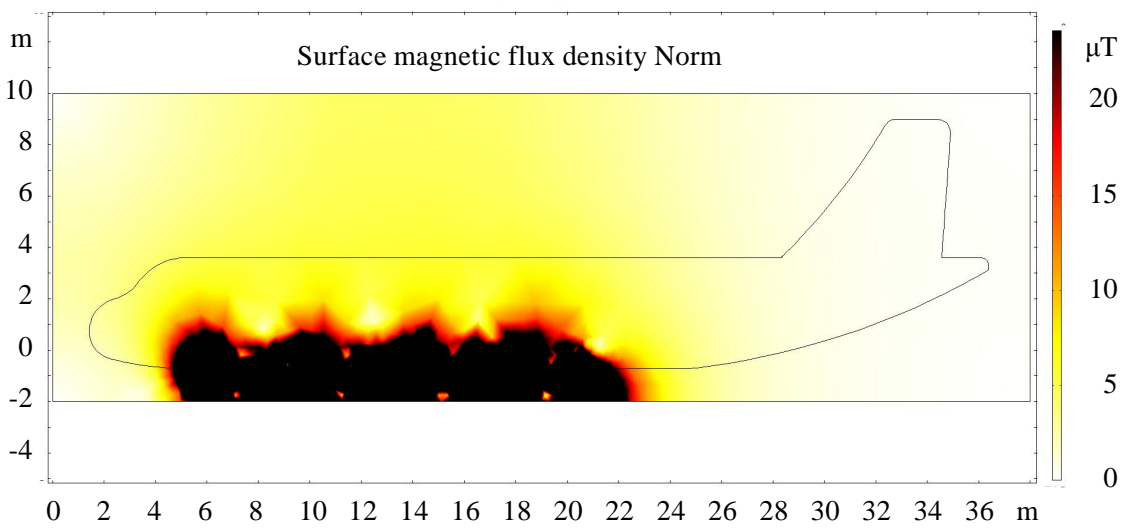

Figure 12. Magnetic induction around the mid-size passenger aircraft accelerating by maglev technology.

- most of people do not know an interesting fact, the railway transport kept safe has a first widely reported railway fatal accident during opening the World first passenger railway line between Liverpool and Manchester [84],

- the Gabriel team had demonstrated the safe, sustainable and cost-effective feasibility of using the MagLev assisted aircraft take-off and landing (see for example the description and discussion of the rendezvous control),

- the new generation is flexible in acceptance of radically new solutions, they will not afraid of travelling on undercarriage-less aircraft.

The Gabriel project [7] had developed special ideas for final positioning the aircraft before touching down to moving platform and different technologies for their fixation of aircraft promptly after touch down on cart-sledge system.

The safety of Gabriel concept was studied [7] by use of generally recommended and accepted methods. The ground-based system and the take-off phase was evaluated at the developing the concept already by detailed product tree and a functional analysis for the ground based system elements, and a detailed failure modes and effects analysis was conducted to airborne phase. A critical item list was created and a detailed list of requirements was developed for the elements in the product tree, including e.g. the guideway, the propulsion, the power chain, the sledge, the cart, and the aircraft.

A product tree and functional analysis for the rendezvous control system was made, too. With the defined hazard list and hazard scenarios, a functional failure mode effect analysis was performed. This provided a critical item list, with numerous recommendations and proposals to mitigate the risk, and guarantee safety during the landing phase with the envisioned rendezvous control system.

The critical item list and off-nominal scenarios were recalled for the ground-based system and for the landing phase with a special attention on emergency landing. Adverse weather and external hazards were also extensively addressed.

The analysis shows that, the critical phase of flights is the landing, especially in emergency cases. 
The evaluation results and elaborated recommendations make possible the implementation of the MagLev assisted aircraft into operation without reducing the safety level.

- Emergency landing

The future air passengers have another problem with the undercarriage-less aircraft: what will happen in case of failure in airport ground systems? How may the aircraft land in emergency cases? For giving answer for this disquieting question, at first, the risk of emergency (precautionary, forced and ditching) landing was studied.

Analysis of the emergency situations and forced landings of aircraft shows that the risk of forced landing equals to about $4.5 \cdot 10^{-5}$ per flight and the probability of ditching is $2 \cdot 10^{-6}$ per flight. At the same time only about $3 \%$ of forced landing lead to fatal accident. This means that the risk of fatal forced landing is $1.4 \cdot 10^{-6}$ per flight. Generally, fatalities are observed in $12 \%$ for ditching cases. Therefore, risk of fatal ditching is less than $3 \cdot 10^{-7}$ per flight. Principally, the MagLev assisted aircraft may have the same risk for fatal emergency risk or even the situation is better, because the under surface of the aircraft always is "clear", there is not possible opening of the undercarriage system partly or only one side.

Without regard to this statistics, there were developed several ideas for reducing the serious outcomes from emergency landing of Maglev assisted aircraft by introducing a special supporting system for emergency landing (helping in choosing the landing area even in bad weather condition, optimizing the control for emergency situation depending on the identified failures, developing an electric or diesel engine driven cart for realization the landing at reserve airport without MagLev track and using the lightweight skids opening for forced landing (Figure 13).

\section{Conclusions}

This paper introduced results of an interesting and really out of the box thinking Gabriel project [7] developed original and radically new technology applying the magnetic levitation technology to ground assisting the take-off and landing of an aircraft without conventional undercarriage system. This unique project had demonstrated the feasibility of developing concept that was tested by theoretical (simulation) and practical experiences, when the small UAV model could safely land on the moving electric cart and on built for this purposes $6 \mathrm{~m}$ lengths MagLev track. The impact analysis showed that, the concept might be implemented safely and cost-effectively. On each flight of middle-size passenger aircraft the fuel consumption can be reduced up to $18 \%$ and the cost for 1300 1500 EURs due to re-optimization of the aircraft to use the MagLev technology to assisting the take-off and landing. The concept recommended itself as one of the most powerful methods for further reduction of the environmental impact. During the take-off, depending the applying scenario, the chemical emission might be cut for $40 \%-60 \%$, while the noise up to $64 \%$. 


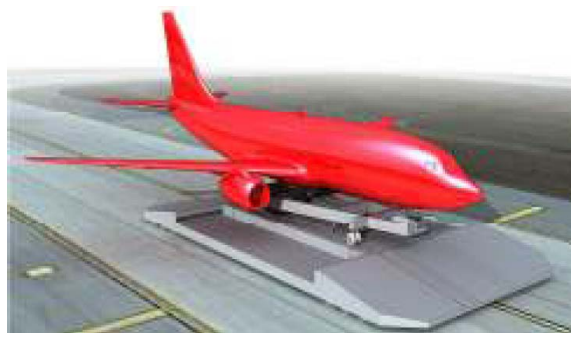

(a)

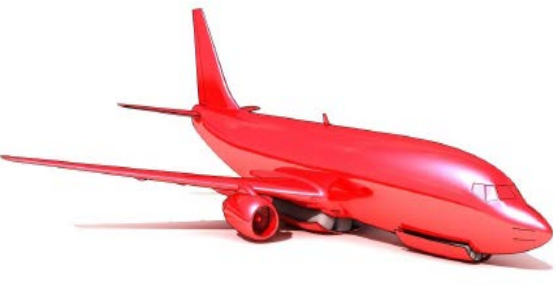

(b)

Figure 13. Landing of undercarriage-less aircraft on the ground moving cars (on own wheels) or on the lightweight skids (opening for forced landing).

The EU supported international Gabriel project had finished in planned time by developing the offered concept and realizing all the planned evaluations, calculations, tests. The results were excellent, or as it can be said better than that were expected. The project maintained the European priority in this research area, using the Maglev technology to assisting the take-off and landing of the civilian passenger aircraft.

Nevertheless, the further research are out of support one of the reason of that might be the stakeholders' fair of using the radically new technologies.

The second part of the paper defined and analysed the development of the radically new technologies, including the 1) definition of the revolutionary new, so called disruptive technologies, 2) methods of technology identification evaluationand selection applicable in development of the radically new solutions and products and 3) conditions of the successful implementation, deployment of the new technologies and products. The paper underlined that the future will be defined by developed disruptive technologies that destroy the existing systems and introducing new systems on higher technological level. The adaption of the technology identification, evaluation and selection method developed by Kirby [58] to selection of the available, new, disruptive technologies for creation radically new products, solutions allows developing such radical solutions as the Gabriel Concept, namely MagLev assisted aircraft take-off and landing. The successful implementation of the radically new technologies is determined by market acceptation, applying methodology and process management and evaluation of the technology and product lives and possible reaching the society acceptances.

The third part of the paper returned to the concept implementation. The problems and barriers impending the use of the MagLev assisted aircraft take-off and landing had been analysed. There were named the most important areas and problems: the special technical, technological problems (required energy support-energy balance, rendezvous control, real environmental impact), problems of stakeholder (required large investments, innovation diffusion and chasm, security) and barriers in society acceptance (possible effects of magnetic fields, safety of landing, emergency landing).

All the major areas and problems had been investigated by the Gabriel project, already. Therefore, after short definition the problems and barriers, there were 
introduced the related results and recommendations of Gabriel project.

This paper has demonstrated that, during development of the disruptive technologies, solutions, the special attention must be spent on working with stakeholders. It is not enough to demonstrate that, the developing radically new technologies might be deployed in safe and cost-effective and greener products, services, but the stakeholders must be accept the implementation of these new technologies (they must believe in there safe operation).

\section{Acknowledgements}

The research of this paper is a part of the GABRIEL project, which received funding from the European Community's Seventh Framework Programme (FP7/2007-2013) under Grant Agreement No. 284884. The authors appreciate the involvement of all consortia members for their contribution. The GABRIEL team includes small innovative companies: Rea-Tech Engineering and Architect Ltd., Slot Consulting (both from Hungary), small advisory expert companies: D. Rogg (Germany), Ad Cuenta (Netherlands), well known universities: University of Salerno (Italy), RWTH Aachen University (Germany), Delft University of Technology (Netherlands), Rzeszow University of Technology and Wroclaw University of Technology (Poland) and large technology transfer institutes: The French Aerospace lab (ONERA-France), Italian Aerospace Research Center (CIRA-Italy) and National Aerospace Laboratory (NLR-Netherlands).

The re-evaluation of the Gabriel project results and special investigation on the stakeholders acceptance of the systems using the disruptive (radically new) technologies or solution was supported by a Hungarian national EFOP-3.6.1-16-2016-00014 project titled, Investigation and development of the disruptive technologies for e-mobility and their integration into the engineering education.

\section{References}

[1] European Aeronautics (2001) A Vision 2020. Report of the Group of Personalities, ACARE, Brussells, 26. http://www.acare4europe.com/docs/Vision\%202020.pdf

[2] European Commission (2011) Flightpath 2050, Europe's Vision for Aviation. Report of the High Level Group on Aviation Research, Directorate-General for Research and Innovation, Directorate General for Mobility and Transport, European Commission, 28.

http://www.acare4europe.org/sites/acare4europe.org/files/document/Flightpath205 0_Final.pdf

[3] ACARE (2011) Strategic Research and Innovation Agenda (SRIA). Vol. 1, 100. http://www.acare4europe.org

[4] National Aeronautics and Space Administration (2002) NASA Aeronautics Blueprint: Towards a Bold New Era in Aviation. Washington DC, 39.

[5] IATA (2013) IATA Technology Roadmap. IATA (International Air Transportation Association, 86.

http://www.iata.org/whatwedo/environment/Documents/technology-roadmap-201 3.pdf 
[6] Truman, T. and de Graaff, A. (2006/2007) Out of the Box, Ideas about the Future of Air Transport, Part 1, ASTERA/ACARE, Koninklijke de Swart, Den Haag, 2006, 108. Part 2, EC Directorate-General for Research, ACARE, Brussels, 2007, 91.

[7] GABRIEL (2011-14) Integrated Ground and On-Board System for Support of the Aircraft Safe Take-Off and Landing-EU FP7 L1 Project, Grant Agreement Number 284884. http://www.gabriel-project.eu

[8] Rohacs, J. and Rohacs, D. (2014) The Potential Application Method of Magnetic Levitation Technology-As a Ground-Based Power-To Assist the Aircraft Take-Off and Landing Processes. Journal of Aircraft Engineering and Aerospace Technology, 86, 188-197. https://doi.org/10.1108/AEAT-01-2013-0017

[9] Rohacs, D. and Rohacs, J. (2016) Magnetic Levitation Assisted Aircraft Take-Off and Landing (Feasibility Study-GABRIEL Concept). Progress in Aerospace Sciences, 85, 33-50. https://doi.org/10.1016/j.paerosci.2016.06.001

[10] Rohacs, J. (2012) GABRIEL Project. Using the Magnetic Levitation Technology to Assisting the Aircraft Take-Off and Landing. 2nd EASN Workshop on Flight Physics and Propulsion, Prague, 31 October-2 November 2012, 16.

[11] Rohacs, J. and Rohacs, D. (2013) Use of Maglev Technology to Assist the Aircraft Take-Off and Landing. The Proceedings of the 1 st International Scientific Workshop Extremal and Record-Breaking Flights of the UAVs and the Aircraft with Electrical Power Plant, Zhukovsky, 23-26 August 2013, 206-219.

[12] Voskuijl, M., Rohacs, D., Rohacs, J. and Schoustra, R.J. (2013) Preliminary Evaluation of the Environmental Impact related to Aircraft. Proceedings of the 4 th Annual International Air Transport and Operations Symposium, Toulouse, 10-12 July 2013, $1-15$.

[13] Falkowski, K. and Sibilski, K. (2013) Magnetic Levitation System for Take-Off and Landing Airplane-Project GABRIEL. COMSOL Conference 2013, Rotterdam, 23-25 October 2013, 7. https://www.comsol.com/paper/download/182061/falkowski_paper.pdf

[14] Schmollgruber, P. (2015) Development of a Certification Module Tailored to Aircraft Multidisciplinary Design Optimization, Challenges in European Aerospace. 5th CEAS Air and Space Conference, Delft, 7-11 September 2015, 15. http://aerospace-europe.eu/media/books/CEAS2015_150.pdf

[15] Sibilski, K., Fakkowski, K., Kaleta, R., Ladyzynska-Kozdras, E., Sibilski-Mroziewicz, A.M. and Wroblewski, W. (2016) Development of the Small-Scale Model of Maglev System Assisted Aircraft Safety Take-Off and Landing. ICAS (International Council of the Aeronautical Sciences) Congress, Daejon, 25-30 September 2016, 9. http://www.icas.org/ICAS_ARCHIVE/ICAS2016/data/papers/2016_0359_paper.pdf

[16] Majka, A. (2013) Flight Path Optimization of an Aircraft Aided during Take-Off by Maglev System. Journal of KONES, 20, 261-268.

[17] Majka, A. (2014) Minimum Emission Unconventional MAGLEV Assisted Take-Off. Journal of KONES, 21, 335-342. https://doi.org/10.5604/12314005.1130481

[18] Majka, A. (2015) Ekonomiczne aspekty wspomagania startu samolotu systemem wykorzystującym technologię magnetycznej lewitacji. Logistyka, 3, 3040-3047.

[19] Majka, A. (2012) Evaluation of the Required Ground Power of a Ground-Based System for Support of the Aircraft Safe Take-Off and Landing. Journal of KONES, 19, 411-418.

[20] Majka, A.R. (2013) Take-Off Aided by Magnetic Levitation Technology. Aircraft Engineering and Aerospace Technology, 85, 435-442.

https://doi.org/10.1108/AEAT-10-2012-0195 
[21] Vos, R., Eeckels, C., Schoustra, R.J. and Voskuijl, M. (2014) Analysis of a Ground-Based Magnetic Propulsion System. Journal of Aircraft, 51, 1013-1022. https://doi.org/10.2514/1.C032555

[22] Wu, P., Voskuijl, M., van Tooren, M. and Veldhuis, L. (2016) Take-Off and Landing Using Ground-Based Power-Simulation of Critical Landing Load Cases Using Multibody Dynamics. Journal of Aerospace Engineering, 29, No. 3. https://doi.org/10.1061/(ASCE)AS.1943-5525.0000520

[23] Majka, A.R. (2016) The Green Trajectory of an Aircraft Aided during Take-Off by Ground-Based System using Magnetic Levitation Technology. Journal of Aircraft Engineering and Aerospace Technology, 88, 432-440. https://doi.org/10.1108/AEAT-11-2013-0207

[24] Rohacs, D., Voskuijl, M., Rohacs, J. and Schoustra, R.-J. (2013) Preliminary Evaluation of the Environmental Impact Related to Aircraft Take-Off and Landings Supported with Ground Based (MAGLEV) Power. Journal of Aerospace Operations, 2, 161-180.

[25] Ladyzynska-Kodras, E., Sibilska-Mrzoiewicz, A., Slawomir, C., Falkowsky, K., Sibilski, K. and Wroblewski, W. (2017) Take-Off and Landing Magnetic System for UAV Carriers. Journal of Marine Engineering and Technology, 16, 298-304.

[26] Wu, P., Voskuijl, M. and Veldhuis, L.L.M. (2017) An Approach to Estimate Aircraft Touchdown Attitudes and Control Inputs. Aerospace Science and Technology, 71, 201-213. https://doi.org/10.1016/j.ast.2017.09.023

[27] Roghacs, D., Voskuijl, M., Pool, D., Soiepenkötter, N. and Sibilski, K. (2018) Aircraft Magnetic Levitated Advanced Take-Off and Landing Concept Validation. Periodica, Polytechnica Transportation Engineering.

[28] GABRIEL (2014) The Magnetic Levitation Runway Concept. Slot Consulting Ltd. https://www.youtube.com/watch?v=snPLWsVruCU

[29] Airbus (2018) Smarter Skies: Eco Climb-YouTube. https://www.youtube.com/watch?v=Un8m6pdQ0D4

[30] Chowson, E. (2010) Konstruktiver entwurf und dimensionierung einer flugzeugseitigen schnittstelle zwischen fahrwerklosen verkehrsflugzeugen und einem bodengebundenen fahrwerksystem. Deutscher Luft-und Raumfahrtkongress 2010, Document ID: 161503.

http://www.mbptech.de/Bilder/(W43-38)161503-DLRK-Vortrag_Erik.pdf

[31] GroLas (2016) mb+Partner Luftfarht technologie. http://www.mbptech.de/GroLaS_en.html

[32] Poudel, K. (2014) Design of Magnetic Levitation Assisted Landing and Take-Off Mechanism of Aircraft using Hammock Concept. International Journal of Engineering Research and General Science, 2, 6-13.

[33] Murugan, M., Nejaamtheen, M.N. and Rajan, S.S. (2013) Conceptual Design of an Aircraft with Maglev Landing System. International Journal of Aerospace and Mechanical Engineering, 7, 1603-1605.

[34] (1946) Electric Catapult Launcher. Science News, 50, 172-175. https://www.sciencenews.org/archive/electric-catapult-launcher?mode=magazine\&c ontext $=3323 \& \operatorname{tgt}=\mathrm{nr}$ https://doi.org/10.2307/3923215

[35] Doyle, M.R., George, S. and Lynne, L. (2000) The Benefits of Electromagnetically Launching Aircraft. Naval Engineers Journal, 78-82. https://doi.org/10.1111/j.1559-3584.2000.tb03306.x

[36] Naval Technology (2017) Gerald R Ford Class (CVN 78/79)-US Navy CVN 21 Fu- 
ture Carrier Programme. http://www.naval-technology.com/projects/cvn-21/

[37] Jacobs, W.A. (2000) Magnetic Launch Assist-NASA's Vision for Future. https://ntrs.nasa.gov/search.jsp?R=20000103883

[38] Emerging (2010) Technologies May Fuel Revolutionary Launcher. http://www.nasa.gov/topics/technology/features/horizontallaunch.html

[39] Batenin, V.M., Bityurin, V.A, Ivanov, G.S., Inozemzev, N.N. and Gorozhankin, P.A. (1997) Electromagnetic Complex Concept for the Horizontal Start and Landing of a Reusable Airspace Aircraft. 48 th International Astronautical Congress, Turin, 6-10 October 1997, IAC Paper IAF-97-V.5.10.

[40] МиГ-АКС (2016) авиационно-космическая система. http://www.testpilot.ru/russia/mikoyan/aks/migaks.htm

[41] Montobbio, F. (1998) Sectorial Specificity in the Relation between Technology and Market Share Dynamics. Cambridge Journal of Economics, 27, 523-545. https://doi.org/10.1093/cje/27.4.523

[42] Dahlman, C. (2007) Technology, Globalization, and International Competitiveness: Challenges for Developing Countries. In: United Nations Department of Economic and Social Affairs, Ed., Industrial Development in the 21 st Century. Sustainable Development Perspectives, United Nations, New York, 29-83. http://www.un.org/esa/sustdev/publications/industrial_development/1_2.pdf

[43] Wahab, S.A. and Osman, S.I.W. (2012) Defining the Concepts of Technology and Technology Transfer: A Literature Analysis. International Business Research, 5, 61-71.

[44] Norman, D.A. (1998) The Invisible Computer, Why Good Products Can Fail, the Personal Computer Is So Complex, and Information Appliances Are the Solution. MIT Press, Cambridge, 302.

[45] Rohacs, J. (2010) Product Development Philosophy. Proceedings of the International Conference on Innovation Technology in Design, Manufacturing and Production, Praha, 14-16 September 2010, 516-520.

[46] Dosi, G. (1998) Sources, Procedures and Microeconomic Effects of Innovation. Journal of Economic Literature, 26, 1120-1171.

[47] Bower, J.L. and Christensen, C.M. (1995) Disruptive Technologies: Catching the Wave. Harvard Business Review, 73, 43-53.

[48] Kroo, I. (2004) Innovations in Aeronautics. 42nd Aerospace Sciences Meeting, Reno, 5-8 January 2004, Paper Number AIAA 2004-0001. https://doi.org/10.2514/6.2004-1

[49] Christensen, C.M., Michael, B.H. and Curtis, W.J. (2008) Disrupting Class: How Disruptive Innovation Will Change the Way the World Learns. McGraw-Hill, New York.

[50] Christensen, C.M. (1997) The Innovator's Dilemma: When New Technologies Cause Great Firms to Fail. Harvard Business School Press, Cambridge.

[51] Christensen, C.M. (1997) Notes on The Innovator's Dilemma: When New Technologies Cause Great Firms to Fail. Harvard Business School Press, Cambridge.

[52] Samuelson, P.A. and Nordhaus, W.D. (2001) Economics. 17th Edition, McGraw-Hill, New York, 792.

[53] Terziovski, M., Samson, D. and Glassop, L. (2001) Creating Core Competence through the Management of Organizational Innovation. Foundation for Sustainable Economic Development, Research Paper. 
[54] Clarke, A. (1999) Evaluation Research: An Introduction to Principles, Methods and Practice. Sage Publications, London, 216. https://doi.org/10.4135/9781849209113

[55] Bakouros, Y. (2000) Technology Evaluation. Report Produced for the EC Funded Project INNOREGIO: Dissemination of Innovation and Knowledge Management Techniques, University of Thessaly, Volos, 37.

[56] Mavris, D.N., Kirby, M.R. and Qiu, S. (1998) Technology Impact Forecasting for a High Speed Civil Transport. World Aviation Conference, Anaheim, 28-30 September 1998, SAE-985547. https://doi.org/10.4271/985547

[57] Mavris, D.N. and Kirby, M.R. (1999) Technology Identification, Evaluation and Selection for Commercial Transport Aircraft. 58th Annual Conference of Society of Allied Weight Engineers, San Jose, 24-26 May 1999, SAWE Paper No. 2456.

[58] Kirby, M.R. (2001) A Methodology for Technology Identification, Evaluation and Selection in Conceptual and Preliminary Aircraft Design. PhD Thesis, Georgia Institute of Technology, Atlanta, 257.

[59] Harris, W.L. (1996) Product and Process: A Very Non-Linear Relationship in Aerospace. In: Sivasundaram, S., Ed., Proceedings of the 1 st International Conference on Nonlinear Problems in Aviation and Aerospace, Embry-Riddle Aeronautical University, Daytona Beach, 693-717.

[60] National (2007) Aeronautics and Space Administration (NASA) Systems Engineering Handbook SP-2007-6105. NASA, Washington DC, 360.

[61] Defence Acquisition University (2001) Systems Engineering Fundamentals. Department of Defence, Systems Management College, Defence Acquisition University Press, Fort Belvoir, 222.

[62] Nieto, M., Lopéz, F. and Cruz, F. (1998) Performance Analysis of Technology Using the S Curve Model: The Case of Digital Signal Processing (DSP) Technologies. Technovation, 18, 439-457. https://doi.org/10.1016/S0166-4972(98)00021-2

[63] Rogers, E.M. (1983) The Diffusion of Innovations. 3rd Edition, Free Press, New York.

[64] Georgiu, L., Harper, C.J., Keenan, M., Miles, I. and Popper, R. (2008) The Handbook of Technology Foresight: Concept and Practice. Edward Elgar Publishing Ltd., Northampton.

[65] Rohacs, D. and Rohacs, J. (2015) Impact of Out-of-the-Box Approach on the Future Air Transportation System. Repüléstudományi Közlemények, No. 3, 189-206. http://www.repulestudomany.hu/folyoirat/2015_3/2015-3-14-0243_Rohacs_D-Roha cs_J.pdf

[66] European Parliament (2015) In-Dept Analysis. European Parliament, Brussels, 28.

[67] Silberglitt, R., Anton, B.A., Landree, E., Pfleeger, S.L., Newton, E.M. and Wu, F. (2006) The Global Technology Revolution 2020, In-Depth Analyses Bio/Nano/Materials/Information Trends, Drivers, Barriers, and Social Implications. RAND National Security Research Division, RAND Corporation, Santa Monica US, 316.

[68] Wüstenhagen, R., Wolsink, M. and Bürer, M.J. (2007) Social Acceptance of Renewable Energy Innovation: An Introduction to the Concept. Energy Policy, 35, 2683-2691. https://doi.org/10.1016/j.enpol.2006.12.001

[69] Chandrasekaran, D. and Tellis, G.J. (2007) A Critical Review of Marketing Research on Diffusion of New Products. Review of Marketing Research, 3, 39-80.

https://doi.org/10.1108/S1548-6435(2007)0000003006 
[70] Peres, R., Muller, E. and Mahajan, V. (2010) Innovation Diffusion and New Product Growth Models: A Critical Review and Research Directions. International Journal of Research in Marketing, 27, 91-106. https://doi.org/10.1016/j.ijresmar.2009.12.012

[71] Sahin, I. (2006) Detailed Review of Rogers' Diffusion of Innovation Theory and Educational Technology-Related Studies Based on Rogers' Theory. The Turkish Online Journal of Educational Technology, 5, 14-23.

[72] Hirschl, B. (2005) Acceptability of Solar Power Systems. A Study on Acceptability of Photovoltaics with Speciasl Regard to the Role of Design. Institute für Ökologische Wirtschaftsforschung, Schriftenreihe des IÖW 180/05, Berlin, 55.

[73] Jager, W., Janssen, M. and Bockarjova, M. (2014) Diffusion Dynamics of Electric Cars and Adaptive Policy: Towards an Empirical Based Simulation. In: Kamiński, B. and Koloch, G., Eds., Advances in Social Simulation. Advances in Intelligent Systems and Computing, Vol. 229, Springer, Berlin, Heidelberg, 259-270. https://doi.org/10.1007/978-3-642-39829-2_23

[74] Bicsák, Gy., Sziroczák, D. and Abbe, G.E. (2015) Electromagnetic Brake/Drive Unit Design for Small Aircraft Environmentally Friendly Ground Operations. IFFK, Budapest, 15-16 October 2015, 106-114.

http://kitt.uni-obuda.hu/mmaws/2015/pages/program/papers/17.pdf

[75] Rohacs, J. and Kasyanov, V.A. (2011) Pilot Subjective Decisions in Aircraft Active Control System. Journal of Theoretical and Applied Mechanics, 49, 175-186.

[76] Tekbas, M.B. and Kale, U. (2017) Subjective Decisions of Car Drivers. Proceedings of 21 st International Scientific Conference, Juodkrantè, 20-22 September 2017, 997-1005.

[77] Rohacs, J., Rohacs, D. and Jankovics, I. (2016) Conceptual Development of an Advanced Air Traffic Controller Workstation Based on Objective Workload Monitoring and Augmented Reality. Journal of Aerospace Engineering, 230, 1747-1761.

[78] Rohacs, J., jankovics, I. and Rohacs, D. (2017) Less-Skilled Pilot Decision Support. 7 th EASN International Conference on Innovation Association in European Aeronautics Research, Warsaw, 26-29 September 2017, 280-302.

[79] Jankovics, I., Tekbas, M.B. and Kale, U. (2017) Developing the Pilot's Load Measuring System. 7 th EASN International Conference on Innovation Association in European Aeronautics Research, Warsaw, 26-29 September 2017, 323-336.

[80] German Aerospace Center (2016) Landing on Moving Car. http://www.dlr.de/dlr/en/desktopdefault.aspx/tabid-10002/\#/DLR/Start/About

[81] Nuworsoo, C. (2009) Preliminaries to a Feasibility Analysis of the Maglev Proposal of the Southern California Association of Governments for the Region. Leonard Transportation Center, San Bernardino, 47.

http://digitalcommons.calpoly.edu/cgi/viewcontent.cgi?article $=1055 \&$ context $=$ crp_f ac

[82] Holmes, B.J. (2009) Innovation in Air Transportation System. Embry-Riddle Aeronautical University, Prescott. http://www.docslide.com/innovation-in-air-transportation-systems/

[83] Magnetic Field Safety Guide (2010) Cornell University, Environmental Health and Safety, Standard Operating Guideline, MFS-1 ver. 4.

http://citeseerx.ist.psu.edu/viewdoc/download?doi=10.1.1.675.1271\&rep=rep1\&type $=\mathrm{pdf}$

[84] Garfield, S. (2003) Last Journey of William Huskisson. Faber and Faber, London, 244. 